\title{
Ecos sociológicos de la axialidad griega. Relectura de Robert Bellah de un legado inagotable
}

\author{
Celso SÁnchez CAPDEQuí \\ Universidad de Navarra \\ celso.sanchez@unavarra.es
}

Recibido: 22-10-2015

Aceptado: 17-02-2016

\section{Resumen}

Este artículo trata la relevancia de Grecia en la construcción de la sociología. Hasta ahora la idea de Grecia estaba fuertemente influenciada por el concepto de secularización. Debido a este concepto, Grecia era el punto de partida de un largo y único proceso histórico de racionalización, que finalizaba con la muerte de la religión y del mito en la sociedad moderna. Las contribuciones recientes de R.Bellah cambian esta imagen. Su investigación empieza con la Era Axial en la que Grecia es el lugar, no la causa, en el que aparece la razón teórica. Ahora en la cultura no desaparece el pasado de la humanidad. Las primeras etapas de la cultura perduran. Por ello, el mito y la teoría son considerados como habilidades y herramientas con las que el hombre moderno organiza la experiencia.

Palabras clave: Era axial; cultura; secularización; teoría; mito.

\section{Sociological Echoes of the Greek Axiality. Robert Bellah's Rereading of an Endless Legacy}

\begin{abstract}
This paper deals with the relevance of Greece in the construction of sociology. Until now the idea of Greece was strong influenced by the concept of secularization. Due to this concept, Greece was the starting point of a long and single historical process of rationalization that finished with the death of the religion and myth in the modern society. The recent contributions of R.Bellah change this image. His research starts with the Axial Age in that Greece is the place, not the cause, where appairs the theoretical reason. Now in the culture the past of mankind doesn't disappear. The first steps of culture remain. Therefore, myth and theory are considered skills and tools with them the modern man organize the experience.
\end{abstract}

Key words: Axial Age; culture; secularization; theory; myth.

\section{Referencia normalizada}

Sánchez Capdequí, C. (2016): “Ecos sociológicos de la axialidad griega. Relectura de Robert Bellah de un legado inagotable", Politica y Sociedad, 53 (3), pp. 713-732.

Sumario: Introducción. 1. En el principio era la Teoría. Grecia en el trasfondo de la secularización. 2. Grecia repensada: los trabajos de S.N.Eisenstadt sobre las civilizaciones axiales. 3. La cultura teórica. Aportaciones de R.Bellah. 4. Conclusión. 5. Bibliografía. 


\section{Introducción}

Grecia y la indagación filosófica siempre han caminado juntas. En nuestra tradición de pensamiento ambas figuras gozan de una estrecha familiaridad cuya duración y firmeza en el tiempo perdura y su influjo sigue activando y nutriendo la memoria de la sociedad contemporánea. Grecia remite al despertar de esos conceptos y prácticas aún vigentes que definen la especificidad irreductible de la condición humana en el marco del hecho natural: la vida especulativa. En ella se sustancia la evocación de ese gesto humano colmado de libertad que es la autorreflexión. La imagen de Grecia coincide con el momento inaugural en el que el hombre se yergue sobre sí mismo y (se) pregunta por la facticidad circundante y sus condicionamientos El hombre ve y va más allá desde la experiencia de asombro ante el mundo con la que profundiza en el abismo insondable que descubre en el cosmos y en sí mismo. Sin embargo, esa visión ejemplar y canónica de Grecia corre el riesgo de convertirse en una figura vaciada de contenido si no se la sitúa en el tiempo y en la historia, si no se toma en consideración esos elementos inadvertidos e inexplorados que promovieron la aparición cultural de su desafío metafísico. De algún modo, imaginamos "el milagro griego sin precursores ni rivales, por así decir, emergiendo de la cabeza de Zeus" (Bellah, 2011: 324).

Grecia aparece en la historia de la modernidad como modelo y referencia inexcusable. Es el principio rector de la cultura humana que señala y encarna el punto de no-retorno que anuncia el despertar de la autoconciencia de la especie. La racionalidad es su gran aportación. Con ello extiende su influencia en el curso histórico y se establece como emblema para el conjunto de la humanidad. No se trata sólo de una facultad de conocimiento. Grecia representa la planetarización de un modelo de vida en torno a la verdad, al método y a la crítica y, por ende, al declive del mito y de la ensoñación imaginaria. Su presencia va diseñando pautas de organización social que desembocan en la centralidad del pensamiento como forma de proceder del hombre con respecto a la naturaleza y a sí mismo. La figura que con más acierto encarna esta profunda mutación cultural es la del filósofo y, en general, la del intelectual, como un actor social que dinamiza las costumbres y moviliza a la sociedad en la búsqueda de las razones y explicaciones de cuanto ocurre (Eisenstadt, 1982: 298ss). De su mano tiene lugar la transformación de "la orgía en sacramento" (Weber, 1992: 245) en un trance histórico en el que la irrupción de las religiones del libro (Judaísmo, Cristianismo e Islam) anuncia la sustitución del ritual sacrificial por el estudio de las escrituras, su memorización y su comentario (Stroumsa, 2009: 88). Sin embargo, Grecia, como se decía arriba, goza de un protagonismo en el conocimiento moderno que conviene precisar. No en vano, lo explica todo sin ser explicado por nada. Disfruta de una autoridad que, en gran medida, viene dada sin haberse especificado suficientemente los motivos de su singularidad a partir de las condiciones sociales, históricas y culturales de su surgimiento.

En este sentido, Grecia no constituye un episodio de renovación cultural aislado. Es parte de un cambio profundo y radical en el rumbo histórico que, en primer lugar, K.Jaspers denomina las revoluciones axiales (1965: 19 y ss). Estas tienen lugar en la primera mitad del s.I a.C. y, con ellas, Jaspers quiere señalar el hecho singular del surgimiento histórico de las civilizaciones como el Israel antiguo, el Cristianismo, el Confucianismo, el Budismo, la Grecia clásica y, posteriormente, el Islam. Este 
conjunto de formaciones culturales, también denominadas por Weber, religiones universales, aparecen casi simultáneamente a lo largo del planeta y su comparecencia supone una transformación de calado en la mentalidad humana: el monismo de las sociedades arcaicas quiebra y emerge una visión dualista basada en dos niveles de realidad: trascendencia e inmanencia. El mundo se parte en dos. Desde este momento el desafío ético de la salvación del alma centra la atención del comportamiento humano. La trascendencia se convierte en el foco de los problemas de la dimensión intramundana. Las grandes preguntas obligan a la condición humana a abandonar la experiencia inmediata en busca de las razones especulativas de cuanto (le) ocurre. Grecia pertenece a este proceso universal de transformación del diseño del mundo. Es axial. Y ello supone, como afirma Jaspers, que no es la fuente, la única fuente, del saber humano en su lucha victoriosa contra la superstición. Se trata de una civilización que convive con otras, que promueve una determinada posición del hombre en el mundo y que experimenta con rasgos singulares esa transformación cognitiva centrada en la aparición del dualismo trascendencia e inmanencia.

La específica manera de definir esta relación entre los dos niveles de realidad es lo que explica la relevancia de Grecia en el curso posterior de la historia judeo-cristiana y universal, que hasta fechas recientes se han solapado. Su episodio cultural recuerda, en gran medida, a escenarios y situaciones que parecen reproducirse en el presente. Al decir de Eisenstadt, la modernidad bebe de esa revolución especulativa acaecida en Grecia desde el momento en que contempla su relación con el mundo a partir de "una apertura sin precedentes" (Eisenstadt, 2007: 260) que define las debilidades y las fortalezas del hombre ante las interrogantes surgidas de la experiencia. Eso explica la definición de Grecia como inicio de un despertar que se estabiliza en el tiempo histórico $\mathrm{y}$, en buena medida, en el actual, y que permite al hombre llegar hasta las frágiles costuras de las cosas que le rodean y hasta al sello convencional que las constituye.

El hombre griego mira a la bóveda trascendente a través de la especulación, no mediante la vía mística o profética, como en el budismo o en Israel respectivamente. Si bien en todos estos casos, el mundo se rasga en los planos trascendente e inmanente, en el caso griego no hay constancia de una trascendencia de tipo religioso ni de un poder centralizador que vele por la ortodoxia doctrinal en la inmanencia. Muy al contrario, la trascendencia expresa un carácter secular, centrado en la idea de bien, al que sólo un modo de vida disciplinado, sistemático y metódico, como el filosófico, puede acceder. Aquí radica la singularidad de la axialidad griega. La creatividad, el control de la experiencia y el ingenio científico del hombre de nuestro tiempo sintonizan con una Grecia que revela la pretensión de preguntar a las cosas por su razón de ser y por el misterio que las rodea, sin otros apoyos y soportes que la propia indagación teórica. De algún modo, su aventura intelectual descansa en la convicción de que tras el carácter aleatorio de la experiencia subyace una idea de orden que sólo el modo de vida filosófico puede desvelar.

Sin embargo, la referencia de Grecia que se instala en las ciencias sociales de la modernidad, y que sólo recientemente empieza a tener contestación, es la de constituir, como decía arriba, un episodio cultural que inicia la tarea humana consistente en afrontar y enfrentar las muchas y sutiles resistencias (filosóficas, religiosas, políticas, culturales) 
que cierran el paso a la libertad humana, restringen sus movimientos y bloquean su capacidad de decidir. El marchamo de Grecia en el conocimiento sociológico de la modernidad ha sido el de la emergencia de una facultad que representa el triunfo definitivo de la voluntad humana de vivir en la luz y abandonar las sombras: la racionalidad. Grecia se presenta como el inicio de la ruptura con el mundo de la ensoñación mítica y como el proceso de superación de cosmovisiones extrañas al razonamiento lógico y a la verdad universal. De algún modo, en esta primera fase la sociología acude a una idea de Grecia sublimada sin considerar las circunstancias histórico-sociales sobre las que se erige la metafísica del ser. Grecia es un límite, un umbral desde el que empieza a revelarse el devenir esclarecedor (y redentor) de la razón. Más en concreto, se trata del origen de un proceso histórico de largo alcance que, desde entonces a la actualidad, queda definido por el concepto de secularización. Su presencia supone un corte radical y fundador en la historia que asume, en gran medida, la sociología hasta convertirlo en supuesto básico de buena parte de sus marcos teóricos y conceptos explicativos.

A continuación propongo una reflexión centrada en los debates actuales propios de la sociología en los que, con la vista puesta en aquellos primeros trances de la axialidad griega, se interpretan los desafíos de nuestros sistemas de creencias en sintonía con mutaciones profundas que hoy están teniendo lugar. A tal fin, 1) describo, en primer lugar, el legado griego en la formulación de la sociología clásica: 2) a continuación, expongo las reflexiones sociológicas de S.N. Eisenstadt que anuncian un cambio de perspectiva desde un enfoque diacrónico y centrado en la idea de creatividad social; en tercer lugar, 3) introduzco ciertas reflexiones que cuestionan la imagen de esa primera Grecia con el apoyo de las aportaciones de Bellah centradas en el enfoque sincrónico de la cultura en el que la razón convive con las fases preteóricas de la evolución social. La reflexión se cierra, finalmente, con 4) una conclusión en la que se recoge el desarrollo conjunto de la argumentación.

\section{En el principio era la Teoría. Grecia en el trasfondo de la secularización}

El pensamiento sociológico constituye uno de los pilares de la modernidad. Desde el momento en que ésta se autodefine como episodio histórico basado en la capacidad del ser humano para diseñar su modo de vida e intervenir en la naturaleza, se acentúa la relevancia de la autorreflexión o pensamiento de segundo grado para el tiempo que vivimos (Giddens et al. 1996). Este exige condiciones, instituciones y valores que favorezcan la existencia de actores que se saben protagonistas únicos de sus vidas y que deciden en contextos locales y globales cargados de complejidad. Este aspecto muestra una relación de continuidad con la visión prevaleciente de Grecia en las ciencias sociales. No en vano, el hombre griego, como el hombre moderno, comparten, desde códigos culturales distintos (y enormemente distanciados en el tiempo), el desafío de saberse sujetos de su existencia. Si bien en Grecia la particularidad de un sujeto recae en su condición pasiva, ya que las fuerzas del destino le marcan desde el exterior los límites ante los que se revela, en la modernidad el sujeto destaca más por su condición activa, ya que esos límites que frenan la realización de sus proyectos surgen colateralmente de sus propias decisiones (Ramos, 1999). En todo caso, uno y otro se 
reconocen en su capacidad de reivindicar su voz y su legado en un curso de las cosas al que acaban influyendo. Con independencia de que entre Grecia y la modernidad hayan pasado un sinfín de cosas y hayan existido modelos culturales basados en otras lógicas (por ejemplo, el Medievo cristiano que hace depender de la voluntad divina cuanto acontece en el terreno intramundano), la modernidad ha priorizado durante mucho tiempo una relación de continuidad entre ambos episodios culturales en la que lo axial y, en especial, el caso griego, comparecía como momento inaugural de una travesía histórica y universal que habría de culminar en los modos actuales de convivencia. Más en concreto, en la identidad parachoques, en la que, según Taylor, se apuntala el proceso de secularización y diferenciación entre lo subjetivo, lo objetivo y lo intersubjetivo que caracteriza a las sociedades des-centradas contemporáneas. Se trataría del (presunto) triunfo de lo secular y del debilitamiento de "la visión del mundo post-cósmico" (Taylor, 2007: 26). En sus propias palabras, "lo que propiamente propongo llamar el gran desarraigo, implícito ya en la revolución axial, llega de este modo a su conclusión lógica " (Taylor, 2007: 146).

El argumento que vincula como causa y efecto o principio y fin sendos períodos históricos, forma parte de lo que se ha dado en llamar el proceso de secularización. Con este concepto se ha querido subrayar en el pensamiento sociológico un curso histórico inexorable que explicaría el paulatino deterioro y el debilitamiento de la religión en la vida pública y su concomitante transformación en problema de carácter privado (Casanova, 1994: 11-39). Su papel ha sido vertebrador de la sociología y, en gran medida, de las ciencias sociales, ya que constituye la narrativa de una condición humana que va superando las etapas de sometimiento al poder de agentes externos (magia, superstición, mito e ideologías) hasta acreditarse como sujeto de su propia biografía individual y colectiva. Frente a las posiciones que hoy proponen una mirada más amplia y diversa de la secularización y que trascienden su despliegue creciente, continuo, inexorable y planetario (Knöbl, 2007), ha sido muy común entender secularización como término antagónico al de religión. La nómina de autores formada por Durkheim, Weber, Marx, Freud, Parsons, Mead, entre otros, pensaba a partir de la idea de "una secularización creciente" (Joas, 2012: 30). Más cercano en el tiempo, P.Berger, afirmó en 1968 en el New York Times (Joas, 2012: 31) que en el año 2000 no habría práctica religiosa, sólo fieles aislados que se encontrarían sumidos en un auténtico océano de secularidad. Las excepciones del pensamiento moderno a esta línea fuerte de la sociología han sido pensadores como A.Tocqueville, W.James, J.Burckhardt, E.Troeltsch y M.Scheler. El caso más reciente es el David Martin, que, en el transcurso de su ya larga reflexión, defiende que, como teoría general, la secularización puede encontrarse más presente en los entornos de la tradición cristiana y sólo puede exportarse a otras sociedades introduciendo modificaciones considerables $(1978 ; 2005)$.

Como se ha dicho anteriormente, la secularización ha constituido el pivote en torno al cual ha gravitado la formación de la línea central del pensamiento sociológico hasta fechas recientes: la teoría clásica de la modernización. Ha sido lo que permitía pensar la realidad sin necesidad de ser repensada por nadie. No hacía falta hacerlo. Su consistencia empírica no comportaba duda alguna porque a lo largo de la primera mitad del siglo 20 se iba confirmando en la experiencia moderna basada en la expansión de los 
ideales de la investigación científica, la industrialización y la economía de mercado. Su propuesta evolucionista en la que las formas sociales más simples se transformaban en complejas a través del concurso de la diferenciación funcional constituía el soporte en el que las contribuciones de Weber, Marx, Durkheim, Parsons, Adorno y Horkheimer, Habermas, Luhmann y Taylor, entre los casos más señalados, encuentran sus claves comunes del análisis social. El dato histórico que fija en el tiempo el despertar de la narrativa de la secularización lo aporta, entre otros, Karl Jaspers. Este marca las líneas interpretativas del significado de Grecia para el conjunto de la historia humana.

En concreto, Grecia encarna la victoria definitiva de la racionalidad sobre el mito. Esta idea se corresponde con el punto de no-retorno histórico en el que el hombre se hace consciente de su desajuste en el mundo y, por tanto, de la necesidad de reajustes creativos constantes. Es el despertar de la filosofía y la reflexión ética. De algún modo, "el hombre se eleva a la conciencia de la totalidad del Ser, de sí mismo y de sus límites. Siente la terribilidad del mundo y la propia impotencia. Se formula preguntas radicales. Aspira desde el abismo a la liberación y salvación, y mientras cobra conciencia de sus límites se propone a sí mismo las finalidades más altas. Y, en fin, llega a experimentar lo incondicionado tanto en la profundidad del propio ser como en la claridad de la trascendencia" (Jaspers, 1965: 20). El hombre busca respuesta a las preguntas de ultimidad del plano trascendente en la actividad filosófica, en la realización de ejercicios espirituales, es decir, "una serie de prácticas destinadas a transformar el yo a fin de que alcance un nivel superior y una perspectiva universal" (Hadot, 2006: 317). El legado griego se incrusta en el periplo humano posterior porque le impulsa unilateral e inexorablemente hacia modelos de convivencia y representación centrados en la creciente capacidad explicativa del agente humano. El curso posterior de la historia se define por las resistencias que el propio hombre ha de vencer con el uso de la racionalidad como facultad garante de una luz que orienta el comportamiento humano hacia el Bien Supremo. De algún modo, se trata de una primera versión de la Ilustración, como insinúa Nietzsche, que, a pesar de obstáculos e impedimentos, nada ni nadie puede detener en su marcha triunfal. Las luces, que definen el ascenso revolucionario de la racionalidad moderna, echan raíz en Atenas muchos siglos antes.

En la narrativa propiamente sociológica, decía anteriormente, Grecia encarna la ruptura definitiva con el mundo del mito y la puesta en marcha de una lógica inmanente que culmina en la configuración de la modernidad. En concreto, en la autorreflexividad a la que está llamado el actor contemporáneo. La afirmación de Jaspers de que "la Edad Mítica llegaba a su fin" (Jaspers, 1965: 21) recuerda la afirmación de Weber de que las profecías judías y el racionalismo griego activan un proceso anónimo e impersonal de modernización, en el que la tensión entre los planos ultramundano e intramundano abre la puerta a la ciencia como instrumento de conocimiento racional, y de secularización, toda vez que el centro religioso de las sociedades tradicionales deja su espacio a las sociedades descentradas y despojadas de la troncalidad religiosa cuya capacidad de decisión recae sobre los especialistas técnicos.

Sin embargo, lo que se traduce de esta propuesta medular de secularización en el pensamiento sociológico es la idea de que los hechos humanos tienen una explicación previa y anterior a su realización y, por ende, la acción no añade nada a lo que ocurre. $\mathrm{O}$, 
con más precisión, lo que ha de ocurrir. En este escenario explicativo no hay historia. $\mathrm{Ni}$ noticia de su carácter accidental y aleatorio. No hay contingencia entendida como "lo que no es imposible ni necesario" (Luhmann, 1992: 86). En el intento de la cultura moderna de reivindicar la capacidad agente de los actores sociales frente a la necesidad histórica de la superstición, aparece, según Joas, "una nueva expresión de ocultamiento de la contingencia en la forma de las filosofías de la historia teleológica o evolucionista" (Joas, 2012: 123). La secularización, en sus diferentes versiones tales como diferenciación funcional, revolución, progreso, etc., escenifica el avance humano sin acción, sin ingenio o creatividad, sin decisión ni voluntad. Los actores se echan a un lado del ritmo arrollador de un curso histórico que se retrotrae hasta Grecia y cuyos efectos habrán de consumarse en la modernidad. Todo ello sin rupturas ni discontinuidades históricas. La presencia de la secularización promueve una liberación sin experiencia liberadora y, por tanto, externa y ajena al actor liberado. El reverso de la moneda es el carácter normativo de la teoría clásica de la modernización (Knöbl, 2001:24), que impregna este modelo explicativo que ha definido la voluntad de dominio del pensamiento sociológico hasta la mitad del siglo pasado.

\section{Grecia repensada:}

\section{los trabajos de S.N.Eisenstadt sobre las civilizaciones axiales}

Si hasta los años 60 el paradigma de la secularización ejerce su influencia en la reflexión sociológica bajo el predominio de la teoría de la modernización clásica, a partir de este momento este predominio se pone en cuestión. A pesar de que hasta entonces autores como P. Berger y Th. Luckman inciden en el debilitamiento del hecho religioso y la privatización de la religión, el mundo se prepara para acontecimientos de enorme relevancia en los que la vitalidad religiosa comparece en el centro de la vida pública y como estímulo de la acción social. Ejemplo como la revolución de Irán, el papel influyente de Juan Pablo II en el nacimiento de Solidaridad, la revolución sandinista en Nicaragua y el aparición de la Mayoría Moral y del Fundamentalismo protestante como fuerza política electoral en Estados Unidos, revelan la nueva sensibilidad que se abre paso en ese período histórico. Hasta el propio P. Berger reconoce que sus diagnósticos sobre el futuro de la religión no habían sido confirmados por la experiencia y comienza a hablar de la desecularización del mundo (Berger, 2005). Más en concreto, se trata de momentos históricos en los que ese magma religioso, junto con la pujanza de ideales propiamente seculares como la sacralización de la persona (Joas, 2011), aspiran a alterar el curso (previsible y anodino) de la historia e introducir novedad en términos de cambio social. La caída del bloque soviético y todo lo que ello supuso de reorganización del mapa político del planeta y del reequilibrio entre las potencias mundiales, habla en ese sentido. Si algo caracteriza a esos momentos es, en palabras de Joas, "la idea de autodeterminación, que expresa el anhelo que tienen los sujetos actuantes de reconocer sus órdenes sociales como una obra de su voluntad" (Joas, 2013).

La acción social quiere ser parte de lo instituido y no quedar a expensas de teleologismos que anticipan los cambios en el devenir de la vida social carente de espontaneidad. Con ello, los actores se reivindican como desencadenantes de novedad 
que no limitan su protagonismo al de meros agentes pasivos, sino que piensan e imaginan cursos posibles de acción. Se incorpora la noción de contingencia al debate sociológico en autores como el propio Hans Joas, Cornelius Castoriadis, Alain Touraine, Anthonny Giddens, entre otros. En última instancia, el mundo empieza a cuestionar el providencialismo secular que anunciaba procesos de salvación colectiva en el espacio intramundano desde el momento en que las iniciativas y los consensos sociales quieren incorporar sus ideales a las instituciones rompiendo con esos modelos sociales impuestos desde el exterior. Y, por ello, la imagen predominante hasta el momento de la secularización triunfante por igual en todo el planeta, sin análisis empíricos concretos, se debilita. En palabras, de José Casanova, "la secularización es una categoría que tiene sentido dentro de un contexto de unas dinámicas externas e internas particulares de la transformación de la cristiandad europea occidental desde la Edad Media hasta el presente. Pero la categoría se vuelve problemática una vez que se generaliza como un proceso universal de desarrollo social y cuando se transfiere a otras religiones del mundo y otras áreas civilizacionales con dinámicas muy diferentes a la hora de estructurar las relaciones y tensiones entre la religión y el mundo, o entre la trascendencia cosmológica y la inmanencia profana" (2012: 40).

Bajo esta atmósfera de renovación social y sociológica, aparece la obra de Shmuel $\mathrm{N}$. Eisenstadt. Su campo de investigación no es tanto el debate puramente teórico como el estudio de problemas concretos. Su punto de partida lo constituye un escepticismo de fondo ante los presupuestos de la teoría de la modernización clásica, en concreto, ante el despliegue autodirigido, homogéneo y lineal del proceso de diferenciación funcional que explica, con antelación y sin contrastación empírica, los cambios sociales. Su mirada echa de menos las tensiones, las rupturas y las discontinuidades que surgen con motivo de la intervención de la acción en la configuración del contexto social. La noción de la diferenciación impulsada por la secularización de fondo ha omitido la presencia de las oposiciones y conflictos sociales en torno a los centros de poder y decisión. Se silencia la capacidad de movilización de los grupos sociales orientados al cuestionamiento, renovación y transformación del curso de los acontecimientos. Eisenstadt encuentra su elemento de inspiración en la reflexión de Jaspers sobre las civilizaciones axiales. Desde el momento en que en este período histórico irrumpen la trascendencia y la inmanencia y, con ellas, el papel de los intelectuales en la promoción de visiones y proyectos alternativos a los que la autoridad prescribe socialmente al arrogarse en exclusividad el derecho de representación del misterio trascendente, surge una imagen de la sociedad caracterizada por las tensiones derivadas de la lucha política en torno al control del poder de representación simbólico de la trascendencia. En palabras de Eisenstadt, "el problema de la resolución de la tensión entre el orden mundano y el trascendental es esencialmente irresoluble. Pero la persistente búsqueda de solución da lugar a instituciones reorganizadas, nuevos niveles de conflicto, nuevos procesos de cambio social, así como a una transformación de la relación entre sociedades y civilizaciones“ (1986: 12). La autoridad es cuestionada por problemas sociales como la pobreza, la injusticia y la desigualdad y ha de dar razones a la sociedad y justificar sus decisiones. Asoma la contingencia histórica desde el momento en que irrumpe la idea de que los asuntos humanos carecen del determinismo inexorable propio del 
hecho natural. En definitiva, "intelectuales, sacerdotes, profetas, etc., juegan un papel esencial más importante que antes del tiempo axial ya que, entre otros, tienen el valioso cometido de interpretar con precisión la voluntad inabordable de los dioses" (Knöbl, 2007: 84).

Hasta ese momento en la historia social domina la cosmovisión preaxial, centrada en la visión mítica de la realidad, saturada de densidad religiosa y ajena a los procesos de diferenciación entre lo subjetivo, lo objetivo y lo intersubjetivo. El sujeto social es la comunidad indiferenciada que, en los ritos renovadores de la cohesión social, interactúa con la divinidad venerada. Lo prioritario en ellas es el mantenimiento del orden (y no la idea de salvación) (Beriain, 2000: 29y ss). Estas formaciones preaxiales ignoran la gran aportación axial, la autorreflexividad, y presentan una configuración holista de las cosas a partir de un centro sagrado que apuntala el orden social y cósmico. Entre ellas, cabe incluir a las religiones de la Edad de Piedra así como a las religiones nacionales sacerdotales del Antiguo Oriente Medio de Egipto y Mesopotamia, que comparten estructuras sociales en las que los perfiles diferenciados de la autoridad carismática y política recaen, indiferenciadamente, sobre la comunidad. Sólo con las primeras expresiones embrionarias de Estado la figura del soberano adquiere un relieve diferenciado y privilegiado al que la sociedad reviste de un poder cuasi-divino y sublima bajo la forma de un ser extraordinario (Gauchet, 2005: Cap.1-2).

Frente a la mirada de Jaspers más centrada en la cuestión de la trascendencia, el enfoque de Eisenstadt enfatiza, en mayor medida, el de la creatividad social heredada de las civilizaciones axiales que, desde entonces, palpita en todos los universos culturales y en el propiamente moderno. Su pretensión es la de poner en cuestión el carácter ahistórico de las civilizaciones y descubrir la presencia de la acción en el devenir de las mismas. De algún modo, hacer visible el devenir contingente ocultado bajo la visión mecanicista que predomina en la sociología y la historia. En este sentido, su reflexión se incluye en un Programa de Sociología comparada de las civilizaciones en el que analiza los diferentes episodios por los que atraviesan las civilizaciones, en su intento de dar respuesta a las tensiones interpretativas y políticas que derivan de la distancia entre la trascendencia y la inmanencia (más marcada en unas civilizaciones que en otras). De suerte que esta investigación le permite hablar de modernidades múltiples en la medida en que la idea de autorreflexividad no es monopolio de la modernidad de origen greco-romano y judeo-cristiano, sino que anida como potencialidad a actualizar históricamente en el depósito cultural de las civilizaciones china, hindú, budista y musulmana (Eisenstadt, 2003). El concepto de lo moderno adquiere una variedad de expresiones y formulaciones culturales desconocido hasta la fecha.

Más en concreto, Eisenstadt sitúa a Grecia como una de las civilizaciones en las que más se acentúa la tensión axial trascendencia e inmanencia en la medida en que en ella "existía una fuerte orientación intramundana de la visión trascendental. Esta orientación era manifiesta en un fuerte énfasis en la exploración del cosmos y la "naturaleza" y del orden social y político - y, de alguna manera, también de la naturaleza humana - como los principales dominios de la aplicación de esta visión trascendental" (Eisenstadt, 1986: 29). Sin embargo, no desaparece la vida religiosa en la sociedad griega. Es más, juega un papel destacado en los resortes de legitimación del orden social y político de 
diferentes ciudades-estados y en los códigos cívicos de la ciudadanía (ateniense). Ello obedece a que "la visión trascendental desplegada en Grecia en general y los intentos por reconstruir el orden político en particular se encontraban totalmente desvinculados de las orientaciones ultramundanas" (ibid.: 30 ).

El protagonismo de la elaboración teórica y el debate político en la resolución de las preguntas de ultimidad acerca de la orientación del comportamiento ético en el mundo se corresponde con el hecho de que en la Grecia del siglo V a.C. no existió el dominio de una autoridad que ocupase el centro político. En la polis ateniense que se abre paso en ese período de transición entre el siglo VIII y IV a.C. no hay espacio para una única autoridad política que disponga, en exclusiva, de la representación terrenal de la dimensión trascendente. Se trata de "una sociedad sin rey" (Bellah, 2011: 334) porque, frente a otros complejos axiales en los que la trascendencia sólo es accesible a través de experiencias religiosas (como el misticismo budista o las profecías judías), en Grecia se afronta a través del debate dialéctico. La novedad de la experiencia griega radica en "la formación de la cultura desde la libertad en vez de desde la dominación" (Meier, 2006: 97). En la línea de la herencia axial, lo que se pone de manifiesto es que la comunidad de la polis se encuentra en disposición de reorganizar el diseño del ámbito intramundano. El problema de fondo es la reconstrucción del orden político como algo respecto del cual nada ni nadie tiene la última palabra. Grecia basa su singularidad cultural en la circulación de la palabra, o en la palabra circulando y deshaciendo la consistencia aparente de la realidad inmediata frente a cualquier forma de poder que pretenda su control en exclusividad en nombre de Dios.

Con ello se asume que notas como la elocuencia expresiva, la habilidad argumentativa y la resonancia pública de las palabras son las tramas constitutivas de la organización de la sociedad. A este modelo de convivencia no escapa la existencia de otros elementos como la fuerza, la desigualdad, la violencia, etc. Pero lo esencial radica en la lucha dialéctica como recurso garante de la autoridad política. Y eso afecta a los ciudadanos, a los diferentes sectores de la sociedad, pero también al poder establecido. Dicho de otro modo, este debe dar razón de lo que dice y hace como aval de su gestión. Se trata de la necesidad de legitimar las decisiones que sirven para el buen gobierno de la ciudad. La sociedad está en la obligación de exigir argumentos y, el poder, de ofrecerlos. No existe una representación política ajena al tiempo y al transcurso histórico. La autoridad política está abocada de continuo a justificar sus decisiones. Su vigencia ha de pasar la prueba del paso del tiempo. Grecia asume la construcción de la democracia como forma de organización política instalada en el plano inmanente e intramundano y basada en la lucha dialéctica y el debate. En muchas ocasiones se impone la opresión de los poderes políticos. Pero, en buena medida, la sociedad griega ve en estas situaciones la incapacidad manifiesta para explicar y ofrecer argumentos que legitimen sus actos. Gobernar sin razones, ni argumentos es el comienzo de la tiranía y la pérdida de credibilidad de cualquier forma de gobierno, ya que éste se ha quedado sin palabras y sólo con la contundencia y la facticidad de sus decisiones.

En este sentido, conviene destacar la novedad del "énfasis griego en la exploración intelectual del cosmos y en la elaboración reflexiva del orden político; la articulación del razonamiento era básico para la primera como el desarrollo de la ciudadanía para la 
última" (Arnason, 2001: 161). Sin embargo, la emergencia de la especulación filosófica y el argumento político no se efectúa por medio de la ruptura con los elementos del pasado. Por ejemplo, frente a la cultura china, muy semejante a la griega por el énfasis en lo secular, que culminó en el confucianismo imperial despojado de las creencias religiosas más arcaicas, la tradición griega siguió un camino diferente: "La centralidad y la continuidad de la religión heredada quedó garantizada por su incorporación al orden político reestructurado" (ibid.: 161). La filosofía y la política marcan la pauta del orden social pero no a base de rupturas y quiebras definitivas con el pasado. Este se ofrece como la materia prima simbólica sobre la que se elaboran argumentativamente las decisiones políticas. Lo pre-axial perdura nutriendo el surgimiento axial de la especulación teórica. Al decir de Bellah, "Homero y Hesíodo fueron textos centrales en la educación griega de la antigüedad, pero nunca tuvieron la autoridad de las escrituras hebreas. Los viejos mitos fueron reformulados por poetas y dramaturgos trágicos; criticados y reformados por filósofos; y los nuevos mitos, dioses y diosas se introdujeron desde una variedad de fuentes cada cierto tiempo sin causar excesivas alteraciones" (Bellah, 2011: 326).

En este sentido los símbolos de la religión griega permanecen en el momento del nacimiento de la vida teórica y especulativa ya que apuntalan y asientan las grandes celebraciones rituales de la polis. En estos fastos (sacrificios, banquetes, representaciones y competiciones) la religión hace las veces de sustancia aglutinante desde la que la comunidad se autoconcibe como un cuerpo social diferenciado. Se trataba de "un evento público y atraía a la muchedumbre de espectadores. Al ser convocada al mismo tiempo la ciudad en su conjunto, el desfile podía superar, al menos momentáneamente, las divisiones más profundas de la sociedad griega" (ibid: 346). Estos episodios de efervescencia colectiva sazonada de presencia religiosa eran "expresiones centrales de la auto-comprensión y la solidaridad de la polis" (346). Esto es así hasta el punto de que no existía un monopolio sacerdotal a la hora de organizar y dirigir el rito. No hay figuras jerárquicas que dispongan en propiedad de la representatividad de la ciudad. Esta escapa a cualquier intento de reducir su pluralidad y su conciencia de tal a una visión canónica de la misma. En estos episodios de condensación emocional el nuevo espíritu de la polis orienta la devoción hacia la comunidad como una nueva unidad secular.

En concreto, la figura de Dionisio juega un papel relevante en la cohesión de Atenas. Se trata de una divinidad cuyo simbolismo compensa la especulación teórica reinante en la vida pública de la ciudad. Dionisio es una divinidad que aúna y funde lo que la filosofía y la política separan. Se caracteriza por ser "el dios que llega" (Kerenyi, 1994: 105), que adviene de un territorio desconocido y extraño. Su simbolismo del vino y del exceso remite a "la perspectiva de la llegada, del advenimiento, de un futuro renacimiento de la sacralidad y la divinidad, esto es, de la religión, y concretamente en una época con orientación analítica que en principio ha arruinado las condiciones de dicha llegada" (Frank, 1994:243). Su fortaleza radica en la representación de la ambivalencia como parte integrante de una existencia humana nunca identificada plenamente con la racionalidad. Ligada a los viejos trances esotéricos y mistéricos, Dionisio constituye el elemento integrador de la nueva comunidad política en la medida 
en que su simbolismo del deseo de vivir y de la voluntad del aumento de la vida (ibid.: 35) incluye la efervescencia nocturna como complemento de la reflexividad diurna. La teoría no agota la comprensión del mundo. Y tampoco basta en el debate público basado en la distinción y precisión de las palabras. Dionisio representa la actualidad latente y recurrente de las fuerzas emocionales soterradas que el hombre experimenta sólo en estado de embriaguez y sin el control racional de la vida ordinaria.

\section{La cultura teórica. Aportaciones de R.Bellah}

Ya ha quedado dicho que la experiencia griega ofrece rasgos específicos y singulares. Si bien comparte con el resto de religiones y civilizaciones axiales la dualidad trascendencia-inmanencia, atribuye a la trascendencia una dimensión especulativa de carácter secular que explica el protagonismo de la acción social en el diseño de su propia idea del orden institucional. El dominio intramundano de la política es el campo de pruebas en el que la meditación teórica y el orden social entran en contacto. La aparición de la expresión democrática de la política tiene que ver con el hecho de que la sociedad se sabe causa y efecto de lo que ella es a cada momento. Su lugar no lo ocupa un Dios o el Destino. Y la interacción política, en contacto con la reflexividad teórica, revela la naturaleza mudable e indeterminada de los asuntos humanos. El potencial esclarecedor del mundo eidético se convierte en el recurso empleado por los actores para responder ante las insuficiencias del orden social. Por ello en Grecia la trascendencia no remite a una divinidad alejada del contexto humano al que prescribe y reglamenta comportamientos. Lejos de imaginar un ser todopoderoso provisto de voluntad y sin contacto con el mundo sensible, la mirada griega proyecta un horizonte de inteligibilidad trascendente como dominio privilegiado de la realidad, cuyo conocimiento requiere una vida de estudio disciplinada y sistemática, la filosofía, que, en el caso de Platón, faculta a los pocos que a ella acceden a la noble tarea del gobierno de la ciudad. Filosofía, política y democracia conforman un conjunto de experiencias que van de la mano y que no pueden entenderse las unas sin las otras.

Ahora bien, la aportación del pensamiento de Bellah sobre la peculiaridad del episodio axial griego remite a una concepción de la teoría en la que se ilustra y se documenta la continuidad cultural con el pasado. Si bien el sustrato de la secularización del pensamiento moderno se traduce en una imagen de Grecia como promotora del declive del mito y la religión y fundadora del logos y de una racionalización de las pautas de comprensión y explicación (científica) del mundo, Bellah modifica este modelo de análisis del que él mismo participa en las primeras fases de su obra científica (1991: 20-50). En su Beyond Belief de los años 60 habla de una serie de modelos sociales de religión (primitivo, arcaico, histórico, inicialmente moderno y moderno) que fácilmente parecen corresponderse con una visión evolutiva del hecho religioso en la que la idea de secularización se traduce en la dinámica universal de cambio social que culmina no tanto en la desaparición de la religión como en su transformación bajo el valor de la sacralización de la persona. Las etapas iniciales de la religión quedarían subsumidas y superadas en las expresiones de una religiosidad secular centrada en la troncalidad de la persona y en la influencia del protestantismo para la formación del 
sistema de creencias moderno. En la actualidad Bellah modifica este planteamiento desde otra sensibilidad teórica basada en la idea de continuidad y no de ruptura entre los diferentes episodios de la evolución cultural. Como dice el propio Bellah respecto a la cultura humana, "nada se pierde definitivamente" (2005: 72).

De algún modo, la idea de creatividad auspiciada por Eisenstadt es asumida en el nuevo enfoque de Bellah. La teoría nace integrando y, al mismo tiempo, alterando los episodios previos de la cultura humana. Su capacidad de pensar el mundo en términos universales y de manera abstracta no supone la exclusión de viejos recursos interpretativos que han moldeado y configurado la forma de ver y de estar en el mundo de la criatura humana. Muy al contrario, con la aparición de la teoría "la mente humana comenzó a reflexionar sobre los contenidos de sus propias representaciones, a modificarlas y refinarlas" (ibid: 364). Lo axial sería el acontecimiento histórico en el que, sobre el fondo de todo lo vivido por la humanidad, surge el pensamiento de segundo orden (Elkana, 1986) y el criticismo (Momigliano, 1987), es decir, la capacidad del pensamiento para analizarse a sí mismo y trascender el aquí y ahora. Por supuesto que en las sociedades preaxiales ya existen nociones incipientes de teoría y de pensamiento de primer orden. Ejemplo de ello serían las matemáticas y el comienzo del álgebra en Babilonia. Sin embargo, estos casos destacan básicamente por ofrecer una construcción racional, nunca por ser una reflexión sobre sus fundamentos (Elkana, 1986: 59). La novedad axial consiste en una experiencia histórica en la que la condición humana interroga sobre las condiciones de las certezas socialmente admitidas. En palabras de una voz autorizada en la investigación sobre lo axial y sus vínculos con la modernidad, como la de Björn Wittrock, "la axialidad es una reacción a un nuevo tipo de condición humana en la que ni las estructuras de parentesco ni de proximidad física ni la de los imperios autolegitimados bastan por más tiempo para integrar lo individual en un contexto de significado y familiaridad" (Wittrock, 2012: 111).

Bellah afirma que el proceso de las revoluciones axiales constituye un hito histórico en la medida en que tienen lugar alteraciones de enorme alcance que transforman, desde entonces y de manera inexorable, la vida humana y sus relaciones consigo misma y con el mundo. Recogiendo el testigo del legado de Eisenstadt, Bellah añade que lo axial, que hereda de los modelos sociales preaxiales la existencia de un gobierno central, la planificación urbana y ciertos códigos de diplomacia internacional, se caracteriza, en esencia, por esa dualidad trascendencia/inmanencia, y, al mismo tiempo, por acontecimientos novedosos como la acuñación de la moneda en Asia menor y la sustitución de los cuneados mesopotámicos y los jeroglíficos egipcios por las letras del alfabeto. De especial importancia serían, así mismo, la sustitución del bronce por el hierro y el ascenso del criticismo desde el momento en que los intelectuales influyen en la vida pública añadiendo novedosas interpretaciones de los textos canónicos de la sociedad (Bellah, 2005: 72-73). De estos dos últimos casos, el primero pudo contribuir a una mayor capacidad destructiva en la guerra y al incremento de la productividad en la agricultura, el segundo introduce un avance en la capacidad del hombre para pensar su lugar en el mundo y los condicionamientos del pensar mismo.

Pero, a juicio de Bellah, la argumentación más valiosa, renovadora y bien trabada sobre el alcance de lo axial para la cultura humana se encuentra en la obra del psicólogo 
evolutivo Merlin Donald. Más en concreto, por su gran aportación Origins of Modern Mind (1991). De su mano resitúa su trabajo en el marco de una teoría de la evolución de la conciencia humana mucho más elaborada, basada en las nuevas y enriquecedoras aportaciones realizadas por la psicología del desarrollo cognitivo y evolutivo. Con Merlin Donald, va a proponer un concepto de cultura humana en la que la evolución no cursa por selección sino integrando las facultades precedentes en la más reciente y novedosa. A su juicio, la teoría es "un sistema híbrido" (Bellah, 2001: 364) que no surge del vacío o ex nihilo y cuyo rasgo destacado es el de re-pensar y re-organizar lo heredado, el de intervenir creativamente en el proceso evolutivo que ya no está en manos de la fatalidad natural sino que se inscribe en las tramas de la contingencia. La cultura teórica alienta un giro que, según Donald, "transcurrió desde lo inmediato, la resolución y razonamientos prácticos, hasta la aplicación de esas habilidades a las representaciones simbólicas estables contenidas en las fuentes externas de la memoria" (Donald, 1991:335). En este sentido, la comparecencia histórica de la teoría en Grecia no le otorga a ésta una exclusividad o un privilegio en el uso y el empleo de la misma. Donald concibe a la cultura griega del primer milenio a.C. "como el lugar donde emerge inicialmente la cultura teórica" (Bellah, 2005: 78) pero que, al tratarse de una novedad evolutiva, compromete al conjunto de la humanidad en la tarea de asumir paulatinamente ese potencial autorreflexivo. En este caso, la experiencia griega no supondría el silenciamiento de lo ancestral, todo lo contrario, el primer paso para su tratamiento renovador, reflexivo y crítico.

Donald hace referencia a cuatro fases culturales que ha atravesado la condición humana hasta la aparición de la cultura teórica. Habla de una cultura episódica, en la que el hombre aún no se diferencia de los mamíferos superiores. Su elemento más importante es el de la atención centrada en el "aquí y ahora" sin margen para elaborar una posible cadena de efectos y de eventuales respuestas. El presente inmediato absorbe plenamente la atención. A continuación, hace dos millones de años, surgiría la cultura mimética, en la que la vida humana, aun sin capacidad lingüística, se expresa a través de los movimientos corporales para representar imaginariamente acontecimientos y experiencias de la vida natural y para comunicar con otros actores sociales. Tiempo después, hace 100.000 años, tiene lugar la cultura mítica, con la que, a partir de imágenes y metáforas, la conciencia humana amplía su alcance más allá de la reconstrucción mimética de los hechos dando entrada a una modelización comprehensiva del universo. La narrativa mitológica juega un papel destacado en la capacidad reveladora de sentido de la vida humana. Por último, a mitad del siglo I a.C. nace la cultura teórica, que trae consigo el pensamiento de segundo grado, es decir, la capacidad de repensar lo pensado, de trascender cualquier modelo de conciencia acotado por los límites espaciotemporales hacia formas de representación universales y abstractas. Sin duda que la teoría contribuye a una transformación radical del curso evolutivo de la humanidad toda vez que, por su concurso, las futuras mutaciones del registro cultural ya no son obra de un supuesto determinismo natural. Es decir, puede reobrar creativa y críticamente sobre su pasado sin, con ello, eliminarlo. En palabras de Bellah, "los humanos son criaturas episódicas, miméticas y míticas, si bien, como en las primeras transiciones, la aparición de una nueva forma de la cognición cultural conlleva normalmente la reorganización 
de las primeras formas" (ibid: 78). Nunca su desaparición. Por esa razón, Hans Joas ilustra la posición de Bellah añadiendo que "el "desde" y el "hacia" no significan aquí un proceso de sustitución del uno por el otro. Muy al contrario, la fórmula de Bellah indica que "nada se pierde definitivamente". Lo ritual o lo narrativo, a su juicio, no son superados por lo racional" (Joas, 2011: 89).

Donald explica que las notas específicas de la cultura teórica toman forma de manera gradual en el transcurso cultural de la especie humana. Serían tres: la invención gráfica, la memoria externa y la teoría propiamente dicha. En el primer momento, la representación pictórica basada en imágenes en las cuevas del Paleolítico es el embrión de la posterior aparición de la escritura como recurso que permite la estabilización de la información y, por tanto, la consolidación de la memoria. En este caso, se trata de la memoria externa que al asentarse modifica el estado del cerebro humano desde fuera, ya que interactúa con él introduciendo cambios y alteraciones en sus competencias cognitivas que no hubieran podido surgir desde su propio curso evolutivo. En definitiva, "la invención gráfica y la memoria externa sólo hacen posible los prerrequisitos favorecedores del desarrollo de la cultura teórica, que es la habilidad para pensar analíticamente más que normativamente, para construir teorías que pueden ser criticadas lógica y empíricamente" (Bellah, 2005: 79).

Este esquema de reflexión empleado por Bellah le permite incidir en una visión integradora de la cultura humana que polemiza con la conciencia estadial (Casanova) de la secularización ya que nada del pasado queda excluido. La teoría tiene tras de sí una historia que sigue actuando en su indagación especulativa. Por mucho que haya sido identificada con una habilidad ajena a todo contacto con la experiencia sensible y desvinculada de la influencia del poder sugestivo y equívoco de las imágenes y de la presencia de las reiteraciones miméticas de la representación corporal, estos elementos siguen presentes y actuantes en la reflexión filosófica y en la vida democrática de Grecia. Sin olvidar que el mismo concepto de teoría no surge en el período propiamente axial. Hasta la llegada de la reflexión especulativa el theoros era alguien que viajaba a contemplar y participar como testigo de las celebraciones cívicas o religiosas celebradas en otra ciudad griega (Nightingale, 2006: 40 y ss). Podía tratarse de un desplazamiento oficial o de carácter privado. Igualmente la razón de fondo podía ser por motivos de representación pública o de experiencia religiosa o espiritual personal. Eran tres los destinos del viaje: santuarios religiosos (Delfos), participación en espectáculos (Olimpiadas) y celebración de rituales (representaciones dramáticas y musicales). En todos los casos y cometidos el individuo buscaba la incorporación de una experiencia desconocida y un cierto episodio de conversión de la que luego informar y comunicar. El abandono de la ciudad, la constatación de otros diseños normativos y rituales y el replanteamiento crítico de la experiencia rutinaria conforman un episodio de aprendizaje para sí mismo y para la ciudad. En esta versión pre-clásica y pre-axial de la teoría el componente mimético-ritual y narrativo juega un papel destacado. El theoros busca y se funde con el clima de celebración en el que descubre una experiencia inédita en su vida. Se trata del episodio anterior a la versión especulativa de la teoría en la que aquel momento de implicación afectiva con la experiencia perdió vigor. 
En este orden de cosas también se puede constatar que el papel relevante del pensamiento filosófico en la formación del complejo axial griego es incomprensible sin la presencia de los episodios culturales mimético y mítico. En el primer caso, en las primeras formulaciones del pensamiento filosófico, como la de los jonios Tales de Mileto, Anaxágoras, Anaximandro y Anaxímenes, y en las posteriores más sofisticadas, por ejemplo, de Platón y Aristóteles, la herencia mítica sigue presente de una u otra forma. Lejos de consistir en una reminiscencia del pasado ya superado, el mito constituye la materia prima del emergente pensamiento especulativo. Su componente figurativo y su irradiación metafórica se inscriben en las primeras fases de la indagación teórica. Una vez más, el cambio social no procede a través de cortes y mutaciones bruscas, sino que cursa con lentitud, incorporando nuevas habilidades a las precedentes y sin erosionar el pasado. Así las cosas, el primer esbozo de la actividad especulativa, la filosofía presocrática, se edifica sobre $<$ un marco fundamentalmente narrativo y la creencia de que el cosmos está vivo" (Bellah, 2011: 367).

Los "primeros filósofos", por un lado, se sirven de la estructura del pensamiento épico para ilustrar el carácter dinámico y semoviente del hecho natural. La evocación de los elementos como el agua, el aire, la tierra y el fuego, encarna el comienzo (arje) de las cosas y lo hacen describiendo la historia de la vida del mundo como un proceso de evolución y diferenciación gradual del apeiron (infinito). El imaginario de la materia, como diría Gaston Bachelard (1993: 13), constituye la materia del imaginario, que activa el primer esbozo de un pensamiento abstracto emergiendo de la trama míticanarrativa aún presente. No hay ruptura porque sigue viva la potencia densa y asociativa del mito. No desaparece el matiz a pesar de que surge lo universal. Este incorpora la riqueza semántica de aquel. El mundo se dice a través de la pigmentación cromática del simbolismo mítico por mucho que las formas conceptuales empiecen a abrirse paso. La filosofía no emerge a pesar de, sino a partir del legado mítico. Más en concreto, el momento inicial de la filosofía consistiría en "un punto medio entre mitoespeculación y teoría" (Bellah, 2011: 366). En los primeros filósofos presocráticos, en su reflexión sobre el principio del cosmos, se revive en gran medida la "época arcaica" de la civilización griega en la que Hesíodo da inicio a su Teogonía (Hesíodo, 1993: 27-66) con una cosmogonía basada en entidades naturales, no en los dioses. Es decir, aún no hay referencia a las formas antropomórficas de los dioses olímpicos. Más bien, todo se explica por obra de fuerzas impersonales que carecen de voluntad e intención. En este sentido, la huella del mito y lo narrativo no se ha diluido. Es más, los vínculos con la teogonía de Hesíodo son evidentes.

Por otro lado, un autor tan relevante como Platón para la conformación del pensamiento filosófico griego y universal no se limita al empleo de la vía argumentativa. Su contribución intelectual no pasa por diseñar la nueva tradición del logos reprimiendo la del mito. Sabedor de la arraigada presencia en la Grecia de su tiempo de la cultura oral y de las performances rituales de los bardos en sus episodios de recitación y rapto, Platón opta por el encaje innovador de mito y logos en su propuesta filosófica. En palabras de Bellah, "Platón no rechaza lo mimético y lo mítico - de hecho, considera que sin ellos que no pueden hacer real sus observaciones teóricas. Lo que rechaza no es lo mimético y lo mítico como tal, sólo la tradición conformada por ellos" (Bellah, 
2011: 391). Si bien la verdad necesita de la argumentación teórica típicamente axial, no puede prescindir del capital simbólico y revelador del mito. La contribución de Platón consistió en distinguir por primera vez entre mito y logos, ya que hasta ese momento eran términos sinónimos cuyo significado era relato y narración (ibid:: 389). En Platón el mito es poco fiable porque cuenta narraciones, no argumentos, y sus contenidos se remiten a tiempos remotos y, por ello, incontrastables.

En todo caso, Platón no pretende despojarse de la tradición. Más bien aspira a fundar otra pero basada en la conjunción del carácter troncal del argumento racional sustentado en la abstracción y la universalidad y en la narrativa mítica por tratarse del "modo primario de la expresión de la verdad" (ibid. 393). En este sentido, en una de las obras de mayor calado filosófico y político de Platón, La República, el protagonismo de la narrativa mítica en la elaboración del argumento del autor es incuestionable. Ejemplo de esto sería el mito de la caverna que desarrolla en el citado texto (Platón, 1997: Cap. VII -368-414-) y cuyo contenido es incomprensible sin el recurso a la tradición, en concreto, a la presencia del episodio de la "visita a la muerte" que se recoge en la Odisea de Homero (Homero, 2000: 201-219). Ambos son episodios narrativos pero en el caso de Platón se sitúa en un marco especulativo en el que el mito sigue expresando verdad. Sendos textos comparten la idea de que aquellos que se alzan hasta la vida lúcida de la especulación teórica no quieren volver a la cueva donde sólo se ven sombras que en Homero evocan a la muerte en el Hades. Asimismo, Platón parece apoyarse en el capítulo de "Las razas del metal" recogido en Trabajos y Días de Hesíodo (1993: 67-107) cuando organiza su modelo utópico de sociedad basado en los diferentes regímenes que lo conforman y en el tipo de hombre que representa cada uno de ellos.

En la actualidad uno de los autores que basan sus diagnósticos sobre la modernidad a partir del acercamiento entre mito y logos político es Cornelius Castoriadis. Su texto más destacado, La institución imaginaria de la sociedad (1989), ofrece una reflexión muy original acerca de cómo la creatividad imaginaria constituye el soporte vivo y actuante de todo ideal o significación, que se encarna en el tejido institucional de la sociedad. La creatividad consistiría en esa fuerza anónimo-colectiva que proyecta y condensa ideas, ideales, valores y normas en las que se representan los actores. La fuerza activa de la convivencia emana del magma de la imaginación que no desfallece nunca, que perdura y subyace sincrónicamente bajo el curso anodino y rutinario de la historia. Su actividad conformadora siempre ofrece espacios de apertura semántica y cognitiva con los que los actores pueden responder ante los desafíos del presente. La razón política de la vida social pone nombre, canaliza y critica los excesos de ese despertar impulsivo de la imaginación social. El momento asambleario de la política da forma a la irrupción desbordante de la actividad imaginaria. Por ello, con la mera racionalidad teórica no basta. El bramido de la cultura preteórica sigue participando en la interacción social. Esta sólo es comprensible en esa conjunción de experiencia creativa de la imaginación y el ejercicio de la reflexión de la razón.

En otro orden de cosas, la dimensión mimética de la tragedia ática nutre y forma parte de la reflexión filosófica de Grecia toda vez que su experiencia en las grandes celebraciones ciudadanas golpea directamente a la conciencia de la sociedad revelando la cuestión de los límites de la acción humana. Mímesis y representación teatral y 
pensamiento van de la mano. Al calor de las representaciones públicas los actores meditan las rutinas y los hábitos más arraigados de la ciudad. Con ello, la sustancia mimética de la tragedia ática pone en evidencia lo desconocido y lo ignorado por una conciencia racional que sólo transita por las lógicas del razonamiento especulativo de la vía del ser (Parménides) y orilla las del no-ser referidas a la contingencia, lo accidental y lo aleatorio en la vida social. A través de la representación de las tragedias de Eurípides, Esquilo y Sófocles en los teatros de Atenas la ciudad se convertía en objeto de su propia reflexión desde el momento en que se repensaba y se exponía imaginariamente sus límites ante sí misma. De fondo, late el problema de la democracia y, en concreto, la prevaleciente imagen de autocomplacencia de la ciudad que queda des-figurada en los episodios teatrales. En ellos se hace visible "el ascenso político y cultural de Atenas, su corrupción interna y su decadencia, incluyendo al final los breves períodos de tiranía" (Bellah, 2011: 353).

Las representaciones teatrales hoy pueden tener que ver más con la cultura del entretenimiento y del espectáculo. Sin embargo, en la Atenas del s. V a.C. las piezas trágicas se concebían "al mismo tiempo como una forma de cultura y de obligación cívica" (Bellah: 354). Se trataba de un episodio culminante de la vida política de la ciudad y, lejos de limitarse a ser meros juegos de propaganda política o de relatos moralistas, "ponían en cuestión todo en la tierra y en el cielo" (Bellah: 355). Las zonas opacas y los límites confusos de la racionalidad humana se erigen en tema de reflexión pública. Por eso, conviene tener en cuenta la fecunda vinculación entre la representación mimética y pensamiento. No en vano, en la tragedia la ciudadanía se observa a sí misma como actor y como espectador, de algún modo, la sociedad se observa a sí misma, pero todo ello en la lejanía de un tiempo y un espacio míticos en los que se desarrolla. Junto al Edipo de Sófocles y a sus numerosas interpretaciones relativas a lo mucho que el hombre desconoce de sí mismo y se (le) revela a lo largo de su existencia, un texto ejemplar que expresa la necesidad de incorporar la mímesis trágica en la emergencia del pensamiento especulativo sería Persas de Esquilo, escrito en el año 472, es decir, pocos años después de la gran victoria ateniense en la batalla de Salamina en el año 480 a.C. El texto revela el sufrimiento y la dignidad de los persas, al tiempo que el declive de su imperio. El exceso de la hybris, o ausencia de moderación en las decisiones de sus dirigentes, es el elemento central de su obra. Y ese mensaje se transmitía a la ciudadanía ateniense con el objeto de no cejar en el proceso de autoconocimiento y no permitir caer en la ambición excesiva, como posteriormente ocurrió.

\section{Conclusión}

Grecia siempre ha sido la filosofía. Y la filosofía, para el pensamiento moderno y para la sociología, ha consistido en el hito inaugural de la narrativa ascendente, omnisciente y dominadora de la racionalidad (occidental) en el mundo. Sin alusiones a sus procesos históricos y sociales de gestación, la imagen sublimada y purificada de la metafísica griega aparece en la cultura moderna como el despertar del hombre teórico caracterizado por el uso exclusivo y excluyente de la lógica especulativa. Su aparición histórica 
enterraba definitivamente la voz milenaria del mito y de las facultades ancestrales de la condición humana totalmente ajenas a la interpretación lógica de la realidad.

Sin embargo, tras indagar en los acontecimientos históricos-diacrónicos (Eisenstadt) y culturales-sincrónicos (Bellah) del surgimiento de la axialidad griega, la visión de ésta cambian los ojos de la teorización sociológica actual. Ya no se trataría tanto de una ruptura con el pasado, como del lugar y del entorno cultural en el que asoma la facultad teórica que se convierte en patrimonio del conjunto de la humanidad. Grecia ve surgir en sus tramas culturales la novedad de la racionalidad. Sin embargo, el filósofo no sustituye al chamán, al rapsoda, al místico o al profeta. Es un perfil más que se añade al extenso repertorio de máscaras adquirido por el hombre a lo largo de su historia y cuyo rasgo principal es el de representar con distancia el alcance y el significado de cada uno de ellos. Grecia encarna la creatividad humana constituida de mito-logía. Su singularidad, como subrayó Bellah en su último período de reflexión, consistió en transformar el pasado cultural, nunca en superarlo.

\section{Bibliografía}

Arnason, J.P., "Autonomy and Axiality: Comparative Perspectives on the Greek Breakthrough", en P. Arnason y P. Murphy (eds.), Agon, Logos, Polis, Stuttgart, Franz Steiner Verlag, pp.155-206.

Bachelard, G. (1993): El aire y los sueños, México, F.C.E.

Bellah, R.N. (1991): Beyond Belief, California, University California Press, pp. 20-50.

Bellah, R.N. (2005): "What is Axial about the Axial Age?", Archives Européennes de Sociologie, XLVI (1), pp. 69-87.

Bellah, R.N. (2011): Religion in Human Evolution, Cambridge, Mass, The Belknap Press of Harvard University Press.

Berger, P. (ed.) (2005): The Desecularization of the World, Washington, Ethics and Public Policy Center .

Beriain, J. (2000): La lucha de los dioses en la modernidad, Barcelona, Anthropos.

Casanova, J. (1994): Public Religions in the Modern World, Chicago, The University of Chicago, pp. 11-31 (cap.2).

Casanova, J. (2012): Genealogías de la secularización, Barcelona, Anthropos.

Castoriadis, C. (1988): La institución imaginaria de la sociedad, Barcelona, Tusquets.

Donald, M. (1991): Origins of Modern Mind, Cambridge, Massachusetts, Harvard University Press.

Eisensadt, S.N. (1982): "The Axial Age: the Emergence of Trascendental Visions and the Rise of Clerics", Archives Européennes de Sociologie, 23, pp. 294-314.

Eisenstadt, S.N. (1986): "Axial Age Breakthrough in Ancient Greece”, en S. N. Eisenstadt (ed.), The Origins and Diversity of Axial Age Civilizations, Nueva York, State University Press, pp. 29-39.

Eisenstadt, S. (2003): Comparatives Civilizations and Multiples Modernities (2Vol.), Leiden, Brill. 
Eisenstadt, S.N. (2007): "La dimension civilizadora de la modernidad. La modernidad como una forma concreta de civilización", en M. Aguiluz y J. Beriain (eds.), Las contradiciones culturales de la modernidad, Barcelona, Anthropos, pp. 260-288.

Elkana, Y. (1986): "The Emergence of Second-Order Thinking in Classical Greece", en S. N. Eisenstadt (ed.), The Origins and Diversity of the Axial Age, Nueva York, State University Press.

Frank, M. (1994): El Dios venidero, Barcelona, Ediciones del Serbal.

Gauchet, M. (2005): El desencantamiento del mundo, Madrid, Trotta.

Giddens, A. et al. (eds.) (1996): Las consecuencias perversas de la modernidad, Barcelona, Anthropos.

Hadot, P. (2006): Ejercicios espirituales y filosofía antigua, Madrid, Siruela.

Hesíodo (1993): Teogonía, Trabajos y Días, Escudo y Certamen, Madrid, Alianza.

Homero, (2009): Odisea, Madrid, Cátedra.

Jaspers, K. (1965): Origen y meta de la historia, Madrid, Revista de Occidente.

Joas, H. (2011): Die Sakralität der Person. Eiene neue Genealogie der Menschenrechte, Frankfort, Suhrkamp.

Joas, H. (2011): "Robert N. Bellah. Religiöse Evolution und symbolischen Realismus", en S.Moebius y D.Quadflieg (eds.), Kultur. Theorien der Gegenwart, Wiesbaden, VS Verlag, pp. 83-91.

Joas, H. (2012): Glaube als Option, Friburgo, Herder.

Joas, H. (2013): La creatividad de la acción, Madrid, C.I.S.

Kerenyi, K. (1994): Dionisios. Raiz de la vida indestructible, Barcelona, Herder.

Knöbl, W (2001): Die Speilräume der Modernisierung, Göttingen, Velbrück Wissenschaft.

Knöbl, W. (2007): Die Kontingenz der Moderne. Wege in Europa, Asien und Amerika, Frankfurt, Campus.

Luhmann, N. (1992): Beobachtungen der Moderne, Opladen, Westdeutscher Verlag.

Martin, D. (1978): A General Theory of Secularization, Oxford, Basil Blackwell.

Martin, D. (2005): On Secularization: Towards a Revised General Theory, Aldershot.

Meier, Ch. "Die griechisch-römische Tradition", en H.Joas y K.Wiegandt (eds.), Die kulturellen Werte Europas, Frankfurt, Fischer, pp. 93-116.

Momigliano, A. (1987): De paganos, judios y cristianos, México, F.C.E.

Nigthingale, A.W., (2006): Spectales of Truth in Classical Greek Philosophy. Theoria in ist Cultural Context. Cambridge (U.K.), Cambridge University Press.

Platón (1997): La República, Madrid, Alianza.

Ramos, R. (1999): "Homo Tragicus", Política y Sociedad, No30, pg.213-240.

Stroumsa, G.G. (2009): The End of Sacrifice. Religious Transformations in Late Antiquity, Chicago, The University of Chicago Press.

Taylor, Ch. (2007): A Secular Age, Cambridge, Mass, The Belknap Press of Harvard University Press.

Weber, M. (1992): Ensayos sobre sociología de la religión I, Madrid, Taurus.

Wittrock, B., (2012): "The Axial Age in Global History", en R.N. Bellah y Hans Joas (eds.), The Axial Age and Its Consequences, Cambridge/Massachusetts, The Belknap Press of Harvard University Press. 